\title{
Diagnostic Inflammation Biomarkers for Prediction of 30-Day Mortality Rate in Acute Cholangitis
}

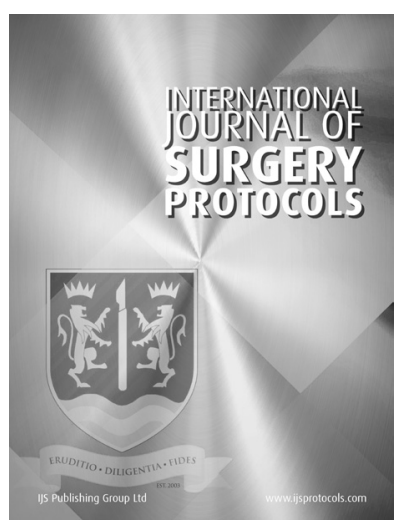

\author{
OMER AL-YAHRI
}

RAED M. AL-ZOUBI (D)

AZZA ALAM ELHUDA

AMINA AHMAD

MAHMOOD AL DHAHERI

*Author affiliations can be found in the back matter of this article
SHERIF ABDELAZIEM

MUSTAFA ALWANI ID

AHMAD R. AL-QUDIMAT

AHMAD ZAROUR
PROTOCOL

\section{IJS Press}

Part of the IJS Publishing Group

\section{ABSTRACT}

Background: Acute cholangitis (AC) is an acute inflammation and infection of the biliary tract, a potentially life-threatening infection, which is usually associated with biliary tree obstruction and impairment of bile flow from the liver to the duodenum. AC is classified by severity from mild, moderate to severe infection (grade I to III, respectively).

Methods: This study recruited a retrospective cohort from Jan 2015 to July 2018. Overall, 294 patients of age $\geq 18$ years with AC were enrolled. The study was conducted according to the World Medical Association Declaration of Helsinki. Demographic and laboratory data were collected for analysis. T-Bilirubin and other laboratory results were collected and analyzed using independent T-test and ANOVA for continuous values and multivariate COX regression for survival analysis for identifying independent factors for early mortality. The cut-off threshold of T-bilirubin was determined by calculating the area under the receiver operating characteristic (ROC) curve.

Results: There were 213 male and 81 female patients and mean age \pm SD of patients was $49.57 \pm 16.1$ and $56.12 \pm 20.18$ respectively. $31.9 \%$ patients were found older than 60 years of age and $35 \%$ patients were found between $30-45$ years of age. T-bilirubin and length of hospital stay (LOS) were found statistically significant $(P<0.05)$ in relation to mortality in $A C$ patients. The area under ROC curve for T-bilirubin level $(P=0.017$, $\mathrm{OR}=1.010)$ was $0.717(95 \% \mathrm{CI}, 6.25-168.9)$ and this is consistent with the Cut-off point for more than or equal to $38.6 \mu \mathrm{mol} / \mathrm{L}(2.26 \mathrm{mg} / \mathrm{dL})$.

Conclusions: In this study, T-bilirubin level is found to be significantly related to short-term mortality in AC. Further studies are still needed with larger cohorts to shed more light on these findings.

CORRESPONDING AUTHOR:

\section{Dr. Raed M. Al-Zoubi, PhD}

Surgical Research section, Department of Surgery Hamad, Medical Corporation, Doha, QA ralzoubi@hamad.qa

\section{KEYWORDS:}

Acute cholangitis (AC); Mortality; biomarkers; diagnosis; T-bilirubin

\section{TO CITE THIS ARTICLE:} Al-Yahri O, Al-Zoubi RM, Elhuda AA, Ahmad A, Dhaheri MA, Abdelaziem S, Alwani M, Al-Qudimat AR, Zarour A. 2022. Diagnostic Inflammation Biomarkers for Prediction of 30-Day Mortality Rate in Acute Cholangitis. International Journal of Surgery: Protocols, 26(1), pp. 14-21. DOI: https://doi. org/10.29337/ijsp.170 
Highlights: Herein, we report a retrospective observational study aiming to evaluate biomarkers contributing to mortality in $\mathrm{AC}$ and to determine the cut-off diagnostic levels that could be easily used in emergency setting. Overall, 294 patients of age $\geq 18$ years with AC were enrolled. The study was conducted according to the World Medical Association Declaration of Helsinki and approved by Institutional Review Board (IRB) with approval: MRC-01-20-823 at Hamad Medical Corporation (HMC). Demographic and laboratory data were collected for analysis. Total-Bilirubin and other laboratory results were collected and analyzed using independent T-test and ANOVA for continuous values and multivariate COX regression for survival analysis for identifying independent factors for early mortality. The cut-off threshold of T-bilirubin was determined by calculating the area under the receiver operating characteristic (ROC) curve. There were 213 male and 81 female patients and mean age \pm SD of patients was $49.57 \pm 16.1$ and $56.12 \pm 20.18$ respectively. $31.9 \%$ patients were found older than 60 years of age and $35 \%$ patients were found between $30-45$ years of age. T-bilirubin and length of hospital stay (LOS) were found statistically significant $(\mathrm{P}<0.05)$ in relation to mortality in AC patients. The area under ROC curve for T-bilirubin level $(P=0.037, O R=$ 1.010) was 0.717 (95\% CI, 6.25-168.9) and this is consistent with the Cut-off point for more than or equal to $38.6 \mu \mathrm{mol} / \mathrm{L}(2.26 \mathrm{mg} / \mathrm{dL})$.

\section{INTRODUCTION}

Acute cholangitis (AC), known from the Greek as angiocholitis (angeion:vessels and khole: bile), is an acute inflammation and infection of the biliary tract, a potentially life-threatening infection that usually associated with biliary tree obstruction and impairment of bile flow from the liver to the duodenum. AC is classified by severity from mild, moderate to severe infection (grade I to III, respectively). Severe acute cholangitis (grade III) is commonly associated with a minimum of one of the neurological, cardiovascular, respiratory, renal, hematological and/or hepatic dysfunctions, that threaten patients' life without the appropriate management and treatment $[1,2]$.

Late diagnosis and delay in both antimicrobial therapy/biliary decompression have been associated with up to $40 \%$ in mortality $[3,4]$. The management for acute cholangitis is mainly conservative and includes intravenous antibiotics and fluids, cessation of oral feeding. Biliary drainage whether endoscopic retrograde cholangiopancreatography (ERCP) and/or surgical intervention and is vital in many cases specially grade II and III, as the management of AC differs according to its severity grades [5]. Many predictors have been assessed for mortality in AC according to Tokyo guidelines [6] and other related studies [7-9] such as age ( $\geq 65$ year), fever (temperature $\geq 39^{\circ} \mathrm{C}$ ), disturbance of consciousness, hypertension, serum creatinine ( $>2 \mathrm{mg} / \mathrm{dL})$, platelet count $\left(<100.000 / \mathrm{mm}^{3}\right)$, hyerbilirubinemia ( $\geq 5 \mathrm{mg} / \mathrm{dL}$ ).

Patients outcomes depend on both severity of AC and time to intervention mentioned previously. The mortality in cholangitis range is between $2.7 \%$ and $10 \%$ in properly and timely managed AC [10-12]. According to 2013/2018 Tokyo guidelines (TG13/TG18), biliary drainage for patients with moderate $A C$ within $48 \mathrm{~h}$ had $50 \%$ reduction in mortality compared to delay in management after $48 \mathrm{~h}$ [13]. Both white blood cell count $(\mathrm{WBC})>10.0 \times 10^{9} / \mathrm{L}$ and C-reactive protein (CRP) level $\geq 10 \mathrm{mg} / \mathrm{L}$ were used as diagnostic criteria for AC in TG18/13 guidelines [13-15]. Finding other useful inflammatory biomarkers for $A C$ is still of great interest for many scholars and commonly markers such as platelet-to-lymphocyte ratio (PLR), neutrophil-to-lymphocyte ratio (NLR), CRP, T-bilirubin, ALP, ALT, Gamma-glutamyl Transferase (GGT), neutrophil and lymphocyte counts have similar discerning powers to WBC. Therefore, more studies to investigate and to evaluate biomarkers in AC patients remain a clinical need. Herein, we report a retrospective observational study aiming to evaluate biomarkers contributing to mortality in $A C$ and to determine the cut-off diagnostic levels that could be easily used in emergency setting.

\section{METHODS}

We conducted a retrospective observational study from 2015 to 2018. We included every patient $(n=294)$ of age $\geq 18$ years with $A C$, who referred to the acute care surgery, Hamad Medical Corporation HMC, Doha, Qatar. Exclusion criteria were any admitted patient of age $<18$ years. Patients were diagnosed according to Tokyo 2018 guideline criteria [16]. The baseline characteristic data of patient, demographics (gender, age, and BMI), laboratory results (Neutrophil-to-Lymphocyte Ratio (NLR), Platelet- 
to-lymphocyte Ratio (PLR), white blood cell count (WBC), hemoglobin (HB), neutrophile, lymphocytes, lactic acid, alanine aminotransferase (ALT), aspartate aminotransferase (AST), alanine aminotransferase (ALP), T-bilirubin, direct bilirubin, albumin, international normalized ratio (INR), prothrombin time (PT), partial thromboplastin time (PTT), creatinine, blood urea nitrogen (BUN) at the time of admission, and duration of hospital stay were collected retrospectively from patient records then stored on spreadsheet for further analysis. The data is collected and summarized in Table 1 and included comorbidities and duration of hospital stay. For the final analysis, laboratory tests with missing data were excluded. The study was conducted according to the World Medical Association Declaration of Helsinki and was approved by the Medical Research Committee at HMC (MRC-01-20-823).

\section{STATISTICAL ANALYSIS}

A multivariate and univariate analysis of laboratory parameters in accordance to mortality were performed. IBM SPSS $23^{\circledR}$ were used to analyze the continuous variables using T-test, ANOVA test, and COX-regression for survival analysis to obtain the odds ratio (OR) with 95\% confidence Interval (CI). The cut-off threshold of T-bilirubin was determined by calculating the area under the receiver operating characteristic (ROC) Curve. P-value under $<0.05$ was considered significant value.

\section{RESULT}

There were 213 male and 81 female patients and mean age \pm SD of patients was $49.57 \pm 16.1(M=48)$ and $56.12 \pm 20.18(M=57)$ respectively. $31.9 \%$ patients

\begin{tabular}{|c|c|c|c|}
\hline PATIENTS BASELINE CHARACTERISTICS & MALE & FEMALE & P-VALUE \\
\hline Gender & $213 / 294$ & $81 / 294$ & NA \\
\hline Age (years) (mean \pm SD) & $49.57 \pm 16.1$ & $56.12 \pm 20.18$ & 0.004 \\
\hline Weight $(\mathrm{Kg})($ mean $\pm \mathrm{SD})$ & $1.69 \pm 0.07$ & $1.57 \pm 0.06$ & 0.001 \\
\hline Height $(\mathrm{cm})($ mean \pm SD) & $73.65 \pm 14.72$ & $69.28 \pm 16.58$ & 0.057 \\
\hline BMI (mean \pm SD) & $25.87 \pm 4.45$ & $28.26 \pm 6.67$ & 0.002 \\
\hline Neutrophil-to-Lymphocyte Ratio (mean \pm SD) & $15.13 \pm 14.52$ & $18.14 \pm 19.43$ & 0.151 \\
\hline Platelet-to-lymphocyte Ratio (mean \pm SD) & $320.39 \pm 263.08$ & $384.20 \pm 390.24$ & 0.108 \\
\hline White blood cell counts $\left(\times 10^{3} / \mathrm{ml}\right)($ mean \pm SD) & $12.33 \pm 5.28$ & $13.10 \pm 7.46$ & 0.319 \\
\hline Hemoglobin $(g / d L)$ (mean $\pm S D)$ & $13.15 \pm 2.23$ & $11.61 \pm 2.18$ & 0.001 \\
\hline Neutrophils $\left(\times 10^{3} / \mathrm{ml}\right)($ mean $\pm \mathrm{SD})$ & $10.22 \pm 5.13$ & $11.09 \pm 6.98$ & 0.247 \\
\hline Lymphocytes $\left(\times 10^{3} / \mathrm{ml}\right)($ mean \pm SD) & $1.13 \pm .811$ & $1.07 \pm 0.79$ & 0.543 \\
\hline Lactic acid $(\mathrm{mmol} / \mathrm{L})($ mean \pm SD) & $2.28 \pm 1.15$ & $2.36 \pm 1.89$ & 0.763 \\
\hline Alanine aminotransferase (U/L) (mean \pm SD) & $182.94 \pm 154.13$ & $246.36 \pm 285.87$ & 0.015 \\
\hline Aspartate aminotransferase $(U / L)$ (mean $\pm S D)$ & $152.78 \pm 136.14$ & $267.99 \pm 378.16$ & 0.001 \\
\hline Alkaline Phosphatase (U/L) (mean \pm SD) & $305.06 \pm 264.66$ & $312.59 \pm 202.70$ & 0.817 \\
\hline Total bilirubin $(\mu \mathrm{mol} / \mathrm{L})($ mean $\pm \mathrm{SD})$ & $89.93 \pm 68.62$ & $77.08 \pm 78.60$ & 0.170 \\
\hline Direct bilirubin $(\mu \mathrm{mol} / \mathrm{L})($ mean $\pm S D)$ & $66.36 \pm 48.70$ & $71.77 \pm 70.90$ & 0.525 \\
\hline Albumin $(g / L)$ (mean $\pm S D)$ & $33.32 \pm 7.64$ & $31.97 \pm 8.16$ & 0.186 \\
\hline International normalized ratio (mean $\pm S D$ ) & $3.14 \pm 23.063$ & $1.50 \pm 1.88$ & 0.560 \\
\hline Prothrombin time (mean \pm SD) & $14.41 \pm 19.56$ & $13.17 \pm 7.58$ & 0.610 \\
\hline Partial thromboplastin time (mean \pm SD) & $33.78 \pm 38.32$ & $28.81 \pm 6.99$ & 0.292 \\
\hline Creatinine $(\mathrm{mmol} / \mathrm{L})($ mean $\pm \mathrm{SD})$ & $96.25 \pm 64.89$ & $99.71 \pm 96.30$ & 0.729 \\
\hline Blood urea nitrogen $(\mathrm{mmol} / \mathrm{L})($ mean $\pm \mathrm{SD})$ & $5.57 \pm 4.11$ & $6.21 \pm 5.24$ & 0.277 \\
\hline Length of Hospital Stay (days) (mean \pm SD) & $10.72 \pm 9.78$ & $11.16 \pm 10.47$ & 0.740 \\
\hline
\end{tabular}

Table 1 Data collected from patient files.

NA: Not applicable. 
were found older than 60 years of age and $35 \%$ patients were found between 30-45 years of age. The baseline characteristics of patients including the laboratory results of this study were collected in Table 1.166 patients (56.4\%) had comorbidities. 42 patients (25.3\%) had hypertension (HTN), 19 (11.4\%) had diabetes mellitus (DM), 64 (38.5\%) had combination of HTN and DM, 41 (24.6\%) had combination of comorbidities as coronary artery disease (CAD), dyslipidemia, cholangiocarcinoma, and chronic kidney disease (CKD). 128 (43.5\%) did not have a comorbid disease as shown in Figure 1. The overall mortality rate was found $3.8 \%(n=11)$.

The cumulative survival and non-survival of this study for the entire cohort is shown in Table 2. Mean survival and mortality age were $50.97 \pm 17.42$ and $61.54 \pm 18.28$ respectively. There was a $96.25 \%(n=283)$ chance of surviving with a mean hospital stay $10.04 \pm 8.39$ days, whereas only $3.74 \%(n=11)$ and $31.45 \pm 20.94$ days for non-survivals.

In multivariate logistic regression analysis using enter method, T-bilirubin found to be a significant predictor of mortality ( $p<0.001)$, while NLR, PLR exhibited no significance (Table 3). In COX-regression survival analysis, T-bilirubin, age, PLR and NLR were identified in Figure 2. T-bilirubin level and age were found statistically significant $(p<0.05)$ to predict mortality giving Hazardous Ratio (HR) 1.010, respectively. The area under ROC curve for T-bilirubin level was 0.717 (95\% CI, 6.25-168.9) and this is consistent with the Cut-off point for more than or equal to $38.6 \mu \mathrm{mol} / \mathrm{L}(\sim 2.26 \mathrm{mg} / \mathrm{dL})$ (Table 3$)$.

\section{DISCUSSION}

The delay in diagnosis and treatment of patients with AC will conceivably aggravate the infection rate and favor the sepsis development, which results in organ failure and shortening patients' life. Number of studies have been reported to determine factors predicting mortality in AC. Although inflammatory biomarkers have been widely used as lymphocyte count, NLR, PLR, serum albumin, creatinine, and CRP, it still have false positive, and negatives results in diagnosis. For instance, Leese et. al. reported a study on the management of acute cholangitis, 94 patients were admitted with $A C$ and enrolled in the study. 60 were women and 34 were men with mean age of 69.7 years and for 20 days hospital stay. 15 deaths (16\%) were reported within 30 days of admission. They found significantly low levels in serum albumin, and high levels in creatinine and urea in $A C$ mortality group compared to the survivors group [17]. Liver abscess, renal failure, liver cirrhosis, malignant stricture, percutaneous transhepatic cholangiography, age older than 50 years and female sex were also

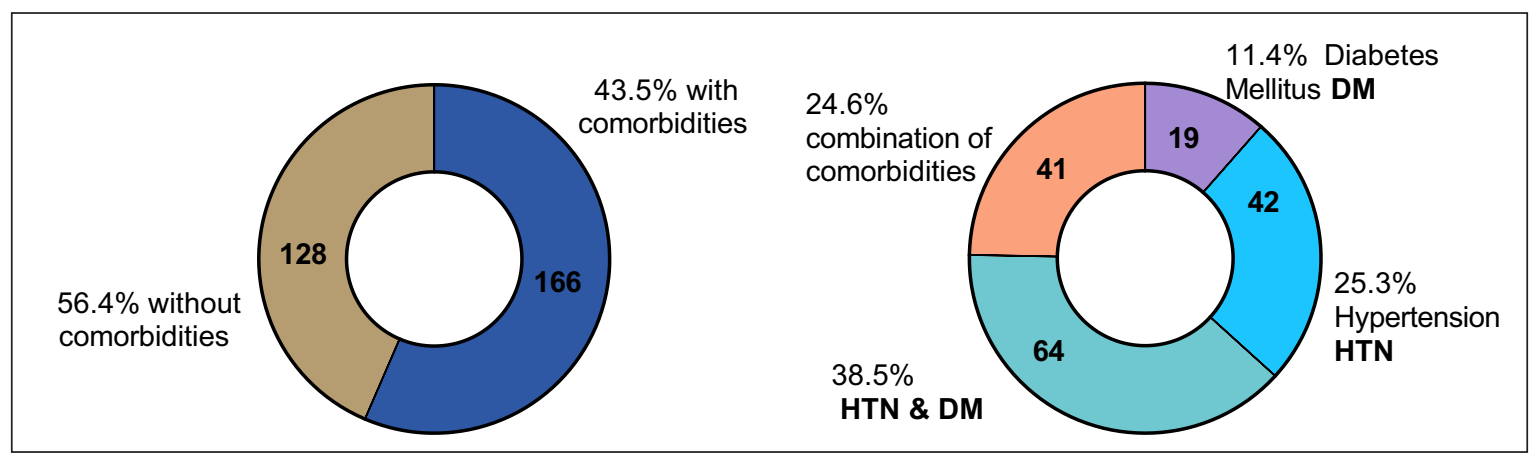

Figure 1 Comorbidities for AC patients enrolled in this study.

\begin{tabular}{|c|c|c|c|}
\hline PARAMETERS & SURVIVAL $(N=283)$ & NON-SURVIVAL $(\mathrm{N}=11)$ & P VALUE \\
\hline Age & $50.97 \pm 17.42$ & $61.54 \pm 18.28$ & 0.05 \\
\hline \multicolumn{4}{|l|}{ Gender } \\
\hline Male (n/\%) & $72.8 \%(n=206)$ & $63.6 \%(n=7)$ & \multirow[t]{2}{*}{0.5} \\
\hline Female (n/\%) & $27.2 \%(n=77)$ & $36.4 \%(n=4)$ & \\
\hline PLR (mean \pm SD) & $340.69 \pm 308.217$ & $267.73 \pm 157.98$ & 0.436 \\
\hline NLR $($ mean \pm SD) & $16.062 \pm 16.109$ & $13.462 \pm 157.98$ & 0.599 \\
\hline Total Bilirubin $(\mu \mathrm{mol} / \mathrm{L})($ mean $\pm S D)$ & $83.09 \pm 67.24$ & $170.69 \pm 120.74$ & 0.037 \\
\hline Hospital stay (days) (mean $\pm S D$ ) & $10.04 \pm 8.39$ & $31.45 \pm 20.949$ & 0.007 \\
\hline
\end{tabular}

Table 2 Demographic data and baseline parameters between survival and non-survival groups.

Data as mean \pm SD or number (\%). SD = standard deviation. NLR = Neutrophil-to-Lymphocyte Ratio. PLR = Platelet-to-lymphocyte Ratio. 


\begin{tabular}{lllll}
\hline MARKERS & P VALUE (2-TAILED) & STANDARD ERROR & HAZARDOUS RATIO & (95\% CI) \\
\hline $\begin{array}{l}\text { T-bilirubin } \\
\text { (Cut-off } \geq 38.6 \mu \mathrm{mol} / \mathrm{L})\end{array}$ & 0.037 & 0.003 & 1.010 & $1.004-1.017$ \\
\hline Age & 0.004 & 0.030 & 1.090 & $1.029-1.155$ \\
\hline PLR & 0.436 & 0.004 & 0.995 & $0.988-1.002$ \\
\hline NLR & 0.599 & 0.032 & 0.968 & $0.910-1.030$ \\
\hline
\end{tabular}

Table 3 Independent marker predictors of mortality in AC identified by multivariate COX-regression survival analysis.

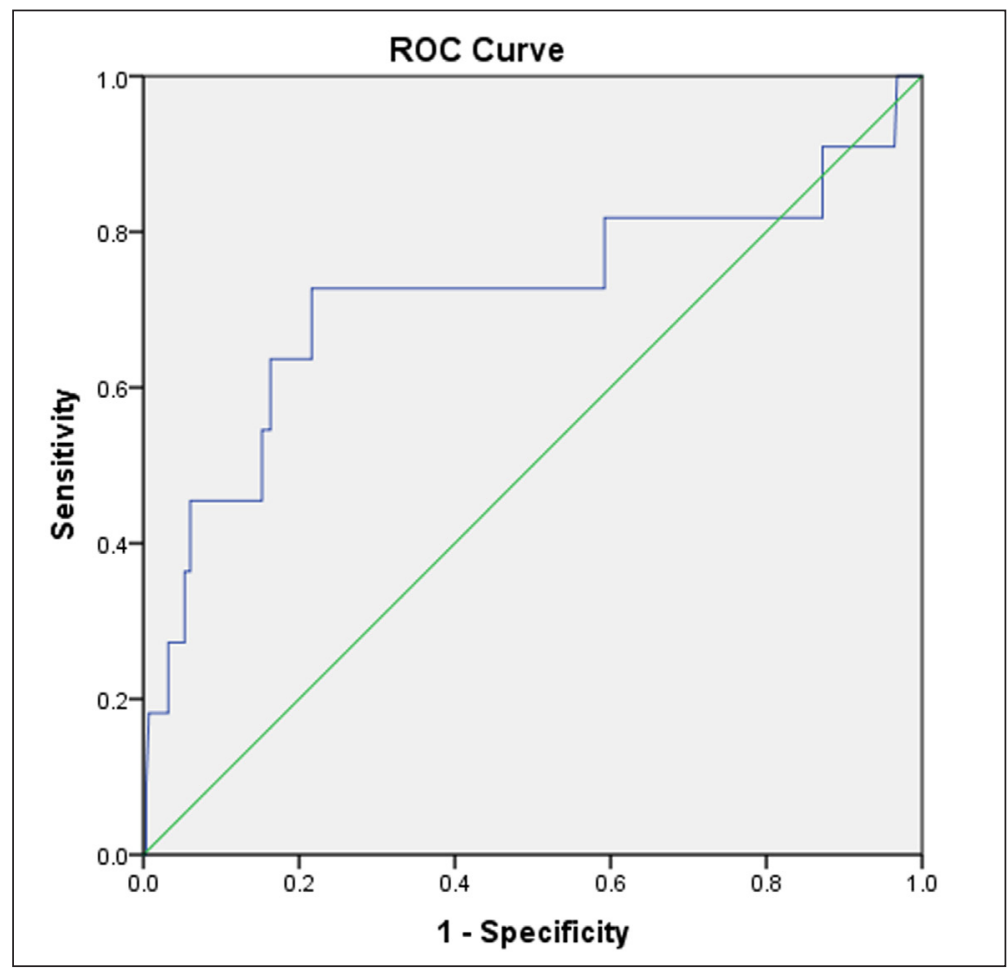

Figure 2 ROC analysis of T-bilirubin in AC patients in the retrospective cohort.

reported as prognostic factors for mortality in AC [18]. Procalcitonin (PCT), WBC and CRP have been widely used as well and performed similar discriminative analysis power in prediction the severity of AC $[19,20]$. In 2018, Beliaev et. al. published a retrospective cohort study of 34 patients with AC and found that lymphocyte count, C-reactive protein (CRP) and neutrophil-to-lymphocyte ratio (NLR) had the highest discriminative analysis powers in diagnosing AC [20].

Same year, Tez and coworkers reported a study of 104 patients with acute suppurative cholangitis (ASC) and proposed a simple scoring system identifying mortality risk in ASC using basic clinical and laboratory tests. They identified red cell distribution width (RDW) as a factor in univariate analysis to predict mortality in cholangitis. Other variables were also identified statistically significant $(p<0.05)$ in multivariant analysis as well such as T-bilirubin level, and intensive care unit admission [21, 22]. In 2016, Schneider et. al. published a retrospective study to create a risk prediction model for AC. 810 patients were selected, and 981 cholangitis episodes were analyzed. 22 predictors, including T-bilirubin, were achieved with good sensitivity and specificity, giving the best validated model performance to predict mortality in AC [23]. Moreover, Lin et. al. found in their retrospective cohort study a clear correlation between neutrophil to lymphocytes ratio and 1 year mortality rate in primary biliary cholangitis [24]. In 2020, Daojun and co-workers reported a study aimed to explore biomarkers for $A C$ with or without sepsis. 65 patients with $A C$ were enrolled in the study and 76 inpatients without AC were selected as control group. PCT was found the best to distinguish sepsis with AC and CRP was found the best to suggest an infection. Soluble triggering receptor expressed on myeloid cells 1 (sTREM-1) was found to be the best biomarker to monitor the response of $A C$ patients to antimicrobial therapy and biliary drainage [25].

More recently, Beliaev and coworkers reported a retrospective cohort study on 212 patients after liver transplantation (LT). $30 \mathrm{LT}$ patients were found with AC and $30 \mathrm{LT}$ patients without $A C$ were randomly selected as a control group. CRP, WBC, lymphocyte and NLR were found to have the highest discriminative powers for diagnosis of AC. CRP was reported to have the best 
discriminative analysis power among LT patients for diagnosis AC and the optimal cut-off point was equal or above $9.5 \mathrm{mg} / \mathrm{L}$ [26]. In 2021, Lavillegrand et. al. reported a retrospective multicenter study included 382 adult patients in intensive care units diagnosed with AC from 2005 to 2018. They identified different risk factors for mortality using multivariate analysis and found T-bilirubin level as one of the predictive factors of mortality [27].

Our study also identified T-bilirubin as a factor predicting mortality in AC. It is not surprising as well that duration of hospital stay would contribute to mortality giving a statistically significant result. There was no statistically significant relationship between PLR and NLR ratio with $A C$ mortality in our study. Hyperbilirubinemia is used as a diagnostic factor in AC, also it is an indicator of cholangitis severity according to TG13/18 especially when its level $>5 \mathrm{mg} / \mathrm{dl}$ (>85.5 $\mu \mathrm{mol} / \mathrm{L}$ ) [6]. Here in our study and also in others, the T-bilirubin is found to be a predictor of mortality as: First, the T-bilirubin is an indicator of severity. Second, the bile duct obstruction could be more sever and lasted for longer duration to raise the bilirubin to higher levels. Furthermore, it indicates the consequence injury to the liver caused by the biliary tree infection and impaired bilirubin excretion process. Finally, to consider the toxic effects of bilirubin itself on deferent organs of the body. These observations could be the justification of correlation between higher T-bilirubin levels and high mortality rate in AC. Consequently, we could say that T-bilirubin is a marker and could be used to predict severity in AC, however more upcoming future studies should be conducted on T-bilirubin as a marker for AC severity. Although good clinical outcomes were observed from this study, the limitations should be considered. Our results represented a retrospective cross-sectional design in which we have no control on the sample size (power of analysis) and from a singlecenter study.

\section{CONCLUSION}

Herein, we suggest a T-bilirubin serum level as a new biomarker to identify risk of mortality in AC using basic laboratory test that is available in most primary care facilities. T-bilirubin levels is found to be largely related to short-term in AC. Clinically, high T-bilirubin level may potentiate a concern regarding poor prognosis and increase mortality risk. Further studies are still needed with larger cohorts to shed more light in these findings.

\section{ACKNOWLEDGEMENTS}

Authors acknowledge the cooperation of Dr. Syed Muhammad Ali, acute surgery division, Hamad Medical
Cooperation, Doha, Qatar for his collaboration and support.

\section{COMPETING INTERESTS}

The authors have no competing interests to declare.

\section{AUTHOR CONTRIBUTIONS}

Omer Al-Yahri, Design and conceptualize the research idea

Raed M. Al-Zoubi, Drafting the work \& interpret the data Azza Alam Elhuda, Collect all data \& lab results Amina Ahmad, Collect all data \& lab results Mahmood Al Dhaheri, Collect all data \& lab results Sherif Abdelaziem, Collect all data $\&$ lab results Mustafa Alwani, Analyzed \& interpret the data Ahmad Al-Qudimat, Analyzed \& interpret the data Ahmad Zarour, Final approval of the version to be published

\section{AUTHOR AFFILIATIONS}

Dr. Omer Al-Yahri, MD (D) orcid.org/0000-0001-9700-2034 Acute care Surgery division, Department of Surgery, Hamad Medical Corporation, Doha, QA

Dr. Raed M. Al-Zoubi, PhD (D) orcid.org/0000-0002-0548-429X Department of Chemistry, Jordan University of Science and Technology, P.O.Box 3030, Irbid, 22110, Jordan; Surgical Research Section, Department of Surgery, Hamad Medical Corporation, Doha, QA; Department of Biomedical Sciences, QU-Health, College of Health Sciences, Qatar University, Doha, 2713, QA

\section{Dr. Azza Alam Elhuda, MD}

Acute care Surgery division , Department of Surgery, Hamad Medical Corporation, Doha, QA

\section{Dr. Amina Ahmad, MD}

Acute care Surgery division, Department of Surgery, Hamad Medical Corporation, Doha, QA

Dr. Mahmood Al Dhaheri MD (D) orcid.org/0000-0001-8195-0486 Acute care Surgery division , Department of Surgery, Hamad Medical Corporation, Doha, QA

\section{Dr. Sherif Abdelaziem, MD}

Acute care Surgery division, Department of Surgery, Hamad Medical Corporation, Doha, QA

Dr. Mustafa Alwani, MD (D) orcid.org/0000-0001-9463-3754

School of Medicine, Jordan University of Science and Technology, P.O.Box 3030, Irbid, 22110, Jordan, JO

Mr. Ahmad R. Al-Qudimat, NP (D) orcid.org/0000-0003-11617244

Surgical Research Section, Department of Surgery, Hamad Medical Corporation, Doha, QA

Dr. Ahmad Zarour, MD (D) orcid.org/0000-0002-7399-5497 Acute care Surgery division , Department of Surgery, Hamad Medical Corporation, Doha, QA 


\section{REFERENCES}

1. Mayumi T, Someya K, Ootubo H, Takama T, Kido T, Kamezaki F, Yoshida M, Takada T. Journal of UOEH. 2013; 35: 249-257. DOI: https://doi.org/10.7888/juoeh.35.249

2. Tsujino T, Sugita R, Yoshida H, Yagioka H, Kogure H, Sasaki T, Nakai Y, Sasahira N, Hirano K, Isayama H, Tada M, Kawabe T, Omata M. European Journal of Gastroenterology and Hepatology. 2007; 19: 585-588. DOI: https://doi.org/10.1097/MEG.0b013e3281532b78

3. Karvellas CJ, Abraldes JG, Zepeda-Gomez S, Moffat DC, Mirzanejad Y, Vazquez-Grande G, Esfahani EK, Kumar A, G. the Cooperative Antimicrobial Therapy of Septic Shock Database Research. Aliment. Pharmacol. Ther. 2016; 44: 755-766. DOI: https://doi.org/10.1111/apt.13764

4. Khashab MA, Tariq A, Tariq U, Kim K, Ponor L, Lennon AM, Canto MI, Gurakar A, Yu Q, Dunbar K, Hutfless S, Kalloo AN, Singh VK. Clin. Gastroenterol. Hepatol. 2012; 10: 1157-1161. DOI: https://doi.org/10.1016/j.cgh.2012.03.029

5. Park TY, Choi JS, Song TJ, Do JH, Choi SH, Oh HC. Dig. Dis. Sci. 2014; 59: 2790-2796. DOI: https://doi.org/10.1007/ s10620-014-3233-0

6. Kiriyama S, Kozaka K, Takada T, Strasberg SM, Pitt HA, Gabata T, Hata J, Liau KH, Miura F, Horiguchi A, Liu KH, Su CH, Wada K, Jagannath P, Itoi T, Gouma DJ, Mori Y, Mukai S, Giménez ME, Huang WSW, Kim MH, Okamoto K, Belli G, Dervenis C, Chan ACW, Lau WY, Endo I, Gomi H, Yoshida M, Mayumi T, Baron TH, de Santibañes E, Teoh AYB, Hwang TL, Ker CG, Chen MF, Han HS, Yoon YS, Choi IS, Yoon DS, Higuchi R, Kitano S, Inomata M, Deziel DJ, Jonas E, Hirata K, Sumiyama Y, Inui K, Yamamoto M. J Hepatobiliary Pancreat. Sci. 2018; 25: 17-30. DOI: https:// doi.org/10.1002/jhbp.512

7. Palmu AA, Saukkoriipi A, Snellman M, Jokinen J, Torkko P, Ziegler T, Kaijalainen T, Hausdorff WP, Verlant V, Kilpi TM. Scand. J. Infect. Dis. 2014; 46: 250-259. DOI: https:// doi.org/10.3109/00365548.2013.876509

8. Schonberg MA, Davis RB, McCarthy EP, Marcantonio ER. J. Am. Geriatr. Soc. 2011; 59: 1444-1451. DOI: https://doi. org/10.1111/j.1532-5415.2011.03523.x

9. Fried LP, Kronmal RA, Newman AB, Bild DE, Mittelmark MB, Polak JF, Robbins JA, Gardin JM. JAMA. 1998; 279: 585-592.

10. Fabre V, Sharara SL, Salinas AB, Carroll KC, Desai S, Cosgrove SE. Clin. Infect. Dis. 2020; 71: 1339-1347. DOI: https://doi.org/10.1093/cid/ciaa039

11. Qin YS, Li QY, Yang FC, Zheng SS. Hepatobiliary Pancreat Dis. Int. 2012; 11: 650-654. DOI: https://doi.org/10.1016/ S1499-3872(12)60240-9

12. Navaneethan U, Jayanthi V, Mohan P. Minerva Gastroenterol. Dietol., 2011; 57: 97-104.

13. Kiriyama S, Takada T, Hwang TL, Akazawa K, Miura F, Gomi H, Mori R, Endo I, Itoi T, Yokoe M, Chen MF, Jan YY, Ker CG, Wang HP, Wada K, Yamaue H, Miyazaki M, Yamamoto M. J. Hepatobiliary Pancreat. Sci. 2017; 24: 329-337. DOI: https://doi.org/10.1002/jhbp.458
14. Miura F, Okamoto K, Takada T, Strasberg SM, Asbun HJ, Pitt HA, Gomi H, Solomkin JS, Schlossberg D, Han HS, Kim MH, Hwang TL, Chen MF, Huang WSW, Kiriyama S, Itoi T, Garden OJ, Liau KH, Horiguchi A, Liu KH, Su CH, Gouma DJ, Belli G, Dervenis C, Jagannath V, Chan ACW, Lau WY, Endo I, Suzuki K, Yoon YS, de Santibañes E, Giménez ME, Jonas E, Singh H, Honda G, Asai K, Mori Y, Wada K, Higuchi R, Watanabe M, Rikiyama T, Sata N, Kano N, Umezawa A, Mukai S, Tokumura H, Hata J, Kozaka K, Iwashita Y, Hibi T, Yokoe M, Kimura T, Kitano S, Inomata M, Hirata K, Sumiyama Y, Inui K, Yamamoto M. J Hepatobiliary Pancreat. Sci. 2018; 25: 31-40. DOI: https://doi.org/10.1002/jhbp.509

15. Yokoe M, Takada T, Strasberg SM, Solomkin JS, Mayumi T, Gomi H, Pitt HA, Garden OJ, Kiriyama S, Hata J, Gabata T, Yoshida M, Miura F, Okamoto K, Tsuyuguchi T, Itoi T, Yamashita Y, Dervenis C, Chan ACW, Lau WY, Supe AN, Belli G, Hilvano SC, Liau KH, Kim MH, Kim SW, Ker CG. J Hepatobiliary Pancreat. Sci. 2013; 20: 35-46. DOI: https:// doi.org/10.1007/s00534-012-0568-9

16. Yokoe M, Hata J, Takada T, Strasberg SM. J Hepatobiliary Pancreat Sci. 2018; 25(1): 41-54. DOI: https://doi. org/10.1002/jhbp.515

17. Leese T, Neoptolemos JP, Baker AR, Carr-Locke DL. Br. J. Surg., 1986; 73: 988-992. DOI: https://doi.org/10.1002/ bjs.1800731214

18. Gigot JF, Leese T, Dereme T, Coutinho J, Castaing D, Bismuth H. Ann. Surg. 1989; 209: 435-438. DOI: https://doi. org/10.1097/00000658-198904000-00008

19. Jiang J, Wang X, Cheng T, Han M, Wu X, Wan H, Daojunyu. Mediat. Inflamm. 2020; 2020. DOI: https://doi org/10.1155/2020/8203813

20. Beliaev AM, Booth M, Rowbotham D, Bergin C. J. Surg. Res. 2018; 228: 35-41. DOI: https://doi.org/10.1016/j. jss.2018.02.048

21. Yıldız BD, Özden S, Saylam B, Martlı F, Tez M. KJMS. 2018; 34: 415-419. DOI: https://doi.org/10.1016/j. kjms.2017.12.016

22. Dixon JM, Armstrong CP, Duffy SW, Davies GC. Gut. 1983; 24: 845-852. DOI: https://doi.org/10.1136/gut.24.9.845

23. Schneider J, Hapfelmeier A, Thöres S, Obermeier A, Schulz C, Pförringer D, Nennstiel S, Spinner C, Schmid RM, Algül H, Huber W, Weber A. BMC Gastroenterology. 2016; 16. DOI: https://doi.org/10.1186/s12876-016-0428-1

24. Lin L, Piao M, Jiang X, Lv H, Zhao N, Yang F, Sun C. BMJ Open. 2017; 7: e01530424.

25. Jiang J, Wang X, Cheng T, Han M, Wu X, X Wan X, Daojunyu. Mediat. Inflamm. 2020; DOI: https://doi. org/10.1155/2020/8203813

26. Beliaev AM, Bartlett A, Bergin C. ANZ Journal of Surgery. 2021; 91: 439-444. DOI: https://doi.org/10.1111/ans.15937

27. Lavillegrand JR, Mercier-Des-Rochettes E, Baron E, Pène F, Contou D, Favory R, Préau S, Galbois A, Molliere C, Miailhe AF, Reignier J, Monchi M, Pichereau C, Thietart S, Vieille T, Piton G, Preda G, Abdallah V, Camus M, Maury E, Guidet B, Dumas G, Ait-Oufella H. Critical Care. 2021; 25. DOI: https://doi.org/10.1186/s13054-021-03480-1 
TO CITE THIS ARTICLE:

Al-Yahri O, Al-Zoubi RM, Elhuda AA, Ahmad A, Dhaheri MA, Abdelaziem S, Alwani M, Al-Qudimat AR, Zarour A. 2022. Diagnostic Inflammation Biomarkers for Prediction of 30-Day Mortality Rate in Acute Cholangitis. International Journal of Surgery: Protocols, 26(1), pp. 14-21. DOI: https://doi.org/10.29337/ijsp.170

Submitted: 07 November 2021 Accepted: 17 December $2021 \quad$ Published: 02 March 2022

COPYRIGHT:

(c) 2022 The Author(s). This is an open-access article distributed under the terms of the Creative Commons Attribution 4.0 International License (CC-BY 4.0), which permits unrestricted use, distribution, and reproduction in any medium, provided the original author and source are credited. See http://creativecommons.org/licenses/by/4.0/.

International Journal of Surgery: Protocols is a peer-reviewed open access journal published by IJS Publishing Group. 